\title{
Determination of Optimal Processing Conditions for the Production of Polyamide 11 Parts using the Laser Sintering Process
}

\author{
http://dx.doi.org/10.3991/ijes.v3i1.4249 \\ A. Wegner ${ }^{1}$, R. Harder ${ }^{2}$, G. Witt ${ }^{1}$ and D. Drummer ${ }^{2}$ \\ ${ }^{1}$ University of Duisburg-Essen, Germany \\ ${ }^{2}$ University of Erlangen-Nuremberg, Germany
}

\begin{abstract}
Due to the advancements during the last decade, the laser sintering process has achieved a high technical level, allowing for Rapid Manufacturing of parts in some applications. However, only few polymers are commercially available for the process. Polyamide 12 dominates the market with share of nearly $90 \%$. Other laser sintering materials differ in part properties from PA 12. Therefore, they are more suitable for some specific applications. Within these, Polyamide 11 has the highest distribution on the market. PA 11 offers some advantages like significant higher part ductility but also some disadvantages like more warpage or higher processing temperatures. However, literature provides in general only little information on the processing of PA 11 and how to achieve optimal processing conditions. A DOE approach using the response surface methodology was utilized to study the correlations between process parameters and part properties. Laser power, scan speed, hatch distance, layer thickness and outline energy density were varied in order to improve the part quality considering mechanical properties, surface roughness and part density. Additionally, results for process influences and part properties were compared with those found for Polyamide 12 in order to derive general correlations. Based on the performed study, optimized process parameter sets are established for PA 11 resulting in improved part properties.
\end{abstract}

Index Terms-Laser Sintering, Polyamide 11, Process Parameters, Process Understanding,

\section{INTRODUCTION}

Increasing competition, decreasing product life cycles, the wish for customized products and a shortage of resources cause the need for innovative manufacturing techniques for small series production [1]. Going beyond the stage of Rapid Prototyping on to Rapid Manufacturing, Additive Manu-facturing offers possibilities for small series production of customized products and an increased freedom of design, due to the lack of tools [2]. The laser sintering of plastic parts is, aside from beam melting of metal parts, one of only two AM-processes which have the capability to be used for Rapid Manufacturing in the near future [3]. In laser sintering parts are built up layer by layer using layer thicknesses between 0.06 and $0.18 \mathrm{~mm}$. The machine produces the parts by repeating three stages for each layer: Firstly, the platform descends by the thickness of one layer. Secondly, powder is spread across the build platform by a leveling roller or coater and preheated to a temperature close to the material's melting point by a radiant heater. Then, a $\mathrm{CO}_{2}$-laser beam melts the powder by tracing the actual cross section line after line, using a scanner system. These steps are repeated until the parts are completed. [4]

In contrast to other plastic processing techniques like injection molding or extrusion, laser sintering works without high pressures. The temperature increase in the powder bed during laser exposure is the driving force in LS. Schmachtenberg developed the idealized process model of isothermal laser sintering which states that the material remains in molten state even after the laser exposure and even when covered with new layers [5]. The melt has in this case a temperature higher than the recrystallization temperature. Existence of this isothermal processing was proven indirectly by evaluation of the spherulite sizes of PP- or POM-parts [6] or directly by temperature measurements within the powder bed [7]. Part properties in LS strongly depend on the interaction of laser energy input, the melt temperature and the melt viscosity during and after the laser exposure.

Laser sintering has reached a high technical level within the past two decades. Most of the information given in the literature on process influences and robust processing were studied for polyamide 12 . In contrast to that, for alternative commercial materials only very few analyses are published. Polyamide 11 has within these materials the highest distribution on the market. It offers some advantages like significant higher part ductility but also some disadvantages like more warpage or higher processing temperatures. However, literature provides in general only little information on the processing of PA 11 and how to achieve optimal processing conditions. Therefore, an enhanced process understanding has to be established. Aim of the research presented here is to establish correlations between process parameters, part's density, mechanical properties and the surface roughness. The resulting correlations can be used to improve process parameters and to establish robust processing conditions.

\section{STATE OF THE ART}

Technical literature contains several papers with analyses and advancements of the laser sintering process. Area energy density $E_{A}\left[J / \mathrm{mm}^{2}\right]$ or Andrew Number $A_{N}$ is often used to describe correlations between process parameters and to compare part properties using different parameter settings. This value for the energy input in laser sintering was introduced by Nelson [8] and is defined as the ratio of fill laser power divided by beam speed, and hatch distance. Starr [9] and Kaddar [10] added powder layer 
thickness as a further parameter to this equation. This modification results in the volume energy density $E_{V}$ $\left[\mathrm{J} / \mathrm{mm}^{3}\right]$.

The correlation between process parameters and mechanical properties of laser sintered parts has been the subject of several analyses in the past and is described in several publications. Gibson presents a study with the aim of understanding the correlation of process parameters and tensile strength as well as part's density while processing polyamide powder on a DTM Sinterstation 2000 [11]. He determined these properties as a function of laser scan speed; hatch distance and laser power. Ho analyzed part's density and mechanical properties of polycarbonate parts as a function of area energy density [12]. Caulfield conducted similar analyses in [13] for Duraform PA. Tontowi determined the density of polyamide parts as a function of energy density in order to build up a model for density prediction [14].

Sauer investigated Duraform PA powder using a DTM Sinterstation 2000. He correlated mechanical properties with different process parameters or multiple part orientations and positions [15]. Further research by Kaddar in [10] additionally aimed at analyzing the influence of different scan strategies on mechanical properties, showing that higher numbers of outline and fill scan counts improve the properties while cross fill scan reduces anisotropy between parts oriented in the xy-plane. He also proved that constant volume energy densities lead to almost identical properties. Starr determined in [9] the influence of laser power on yield stress and elongation for different orientations of specimen. He validated the equation of energy density by varying scan speed, laser power and layer thickness. Starr calculated the minimal energy input needed to melt the powder. He found out, that a volume energy density of at least $0.091 \mathrm{~J} / \mathrm{mm}^{3}$ is needed to fuse the powder. In [16], Jain states a similar minimal energy density of $0.1 \mathrm{~J} / \mathrm{mm}^{3}$. Additionally, he defined a maximum energy density of $0.48 \mathrm{~J} / \mathrm{mm}^{3}$, where polymer degradation starts. In [17], Rüsenberg analyzed the mechanical properties of polyamide parts for increasing laser power and energy density using an EOS EOSINT P390. Additionally, he analyzed part density and porosity. Research done by Pilipovic in [18] demonstrates that even when using the same energy density, differences in mechanical properties can occur.

In addition to the analyses described before, research was done to understand the correlation of different process parameters and part properties in laser sintering, using experimental designs. In [19], Ghanekar presents a study for nylon 12, using "D-Optimal" design, considering powder age, laser power, layer thickness, scan vector length, as well as the part's orientation. He used a Sinterstation 125, which is the first generation of laser sintering systems. In [20], Jain analyzed the influence of refreshing rate, layer thickness, part bed's temperature and hatch pattern on the tensile strength for a constant energy density of $0.0185 \mathrm{~J} / \mathrm{mm}^{2}$. He conducted his experiments using Taguchi's L16 orthogonal array, producing specimen on an EOS EOSINT P380 using PA 2200 powder. The greatest influence results from refreshing rate, layer thickness and part bed temperature. However, the measured values for tensile strength are generally low, due to a low energy density and high layer thicknesses between 0.15 and 0.18 $\mathrm{mm}$. Another analysis for PA 2200 is given by Beal in [21], considering laser power and scan speed. He used factorial design and response surface methodology to correlate process parameters and part's density as well as mechanical properties. For his experiment, he used a prototype laser sintering machine with a low maximum laser power, very low scan speeds and high layer thicknesses. Therefore, the results can only marginally be transferred to commercial laser sintering machines. Monzon, in [22], conducted a study to compare laser sintering machines manufactured by EOS and DTM/3D-Systems with the aim of identifying main influencing factors, using full fractional designs. Laser power and layer thickness were found to be the main influencing factors on mechanical properties. A regression equation was used in order to determine optimal parameter sets. Another approach to correlate process parameters with part properties was performed by Singh [23]. He used response surface methodology based on a central composite design to develop a model in order to predict part's density of polycarbonate parts. The regression equation found shows a non-linear nature of correlations, with all parameters having a significant effect.

In [7, 24- 26] Wegner and Witt performed different studies to establish optimal processing window for polyamide 12. They studied the influence of different parameters like the laser power, the hatch distance, the scan speed, the layer thickness, the powder bed temperature, the material quality as well as the cooling conditions. It was found that in an energy density range between 0.33 and $0.40 \mathrm{~J} / \mathrm{mm}^{3}$ using a layer thickness of $0.1 \mathrm{~mm}$ optimal mechanical properties and high part density can be achieved without occurance of degradation effects. In [27] the same authors studied the influence of process parameters on surface roughness of laser sintered polyamide 12 parts. The results show that besides the parameters for the fill area also the energy density for the outline scan has high influence of surface roughness. In all studies two different laser sintering machines a DTM Sinterstation 2500 (HS) and an EOS Formiga P100 were compared in order to establish general correlations.

However, the presented studies consider only Polyamide 12 or polycarbonate. There are only view studies on Polyamide 11. A first study from 1998 performed by Keller [28] gives some basic results on the material properties and processing of PA 11 . However, no robust processing conditions can be derived from this study. A second study was performed by Goodridge using Duraform EX [29]. She studied the influence of inhomogeneous powder bed temperature on the mechanical properties in building direction. Results show that the influence of local differences in preheating temperatures is much more severe when processing polyamide 11 instead of PA 12 . Grießbach analyzed the influence of energy density on mechanical properties in x-direction of Duraform EX. He found high tensile strength (48 to $51 \mathrm{~N} / \mathrm{mm}^{2}$ ) and Young's modulus (ca. $1600 \mathrm{~N} / \mathrm{mm}^{2}$ ) for energy densities over 0.16 $\mathrm{J} / \mathrm{mm}^{3}$ [30]. In contrast to that, highest elongation at break of $30 \%$ was achieved only for $0.23 \mathrm{~J} / \mathrm{mm}^{3}$. However, detailed correlations, which consider all main influencing factors at the same time, are still missing. Therefore, within the work presented here, the influence of different parameter settings on mechanical properties, density and surface roughness of laser sintered polyamide 11 parts should be analyzed. 


\section{EXPERIMENTAL}

Based on the aforementioned state of the art, the analyses were planned. Tensile specimens according to DIN EN ISO 3167 and density cubes were produced using a DTM Sinterstation 2500HS. Refreshed EOS PA 1101 powder was used for the experiments having an MVR value of $13.5-14 \mathrm{~cm}^{3} / 10 \mathrm{~min}\left(250{ }^{\circ} \mathrm{C}, 5 \mathrm{~kg}\right)$. Basing on preliminary tests, powder bed temperature was set to 187 ${ }^{\circ} \mathrm{C}$.

Specimens for tensile tests were produced in two different part orientations generating each with five specimens and using cross fill scan option. Tensile bars were oriented in $\mathrm{x}$-direction $(\mathrm{x} 0)$ and $\mathrm{z}$-direction (z90). After build process, the specimens were dried in a vacuum oven at $70^{\circ} \mathrm{C}$. The tensile tests in compliance with DIN EN ISO 527-1 and DIN EN ISO 10350-1 were performed using a Zwick testing machine Type 1465 and a testing speed of 50 $\mathrm{mm} / \mathrm{min}$. Additionally, before tensile testing surface roughness depth $\mathrm{R}_{\mathrm{Z}}$ of the tensile bars was analyzed; as defined in DIN EN ISO 4287. The single measuring track was $8 \mathrm{~mm}$, resulting in a total measuring track of $40 \mathrm{~mm}$, using additional $4 \mathrm{~mm}$ at the begin and at the end of the track; according to DIN EN ISO 4288 . $\mathrm{R}_{\mathrm{Z}}$ was measured on the top surface of the $x$-bars and on the side surface of the z-bars using a Mitutoyo tactile surface measurement system SJ-400. For each orientation $R_{Z}$ was measured for three parts making three repetitions per part.

Additionally density cubes were produced in four different sizes $(4 \times 35 \times 15 \mathrm{~mm}, 10 \times 12.5 \times 15 \mathrm{~mm}, 25 \times 12,5 \times 15$ $\mathrm{mm}, 150,12,5 \times 15 \mathrm{~mm})$. In order to study the influence of scan vector length, the parts were only scanned in $\mathrm{x}$ direction. Three parts were built for each size. The density of the smaller cubes (Scan vector length: $4 \mathrm{~mm}, 10 \mathrm{~mm}$ and $25 \mathrm{~mm}$ ) were measured using the Archimedes method according to DIN 1183 . The density of cubes with the dimensions of $150 \times 12.5 \times 15 \mathrm{~mm}$ was determined using a micrometer gauge and an analytical balance due to its size.

A total number of 780 specimens were produced within 3 build jobs to perform the analyses, Fig. 1. The specimens of each parameter set were produced within one build job, being distributed over the build space in order to reduce effects caused by the inhomogeneous temperature distribution on the powder bed surface and also avoiding placement of parts at the edge of the build space.

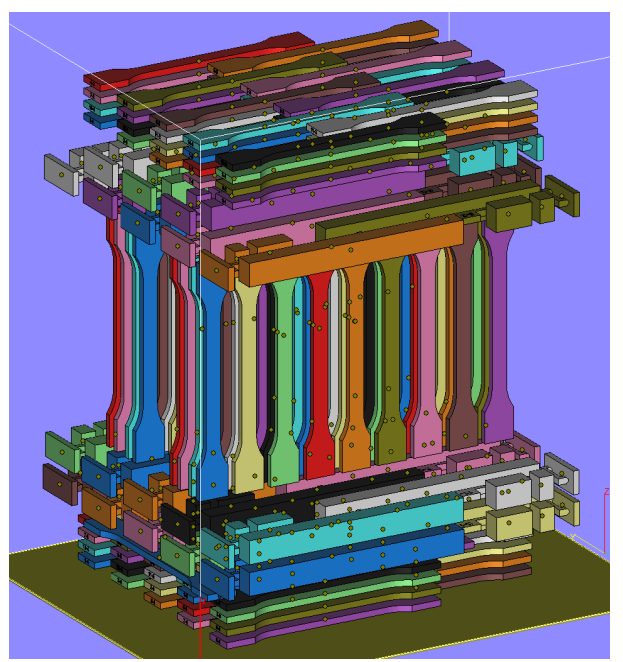

Figure 1. Test build job with placed specimen
TABLE I.

CENTRAL-COMPOSITE DESIGN

\begin{tabular}{|c|c|c|c|c|c|c|}
\hline \multirow{2}{*}{$\begin{array}{c}\text { Exp. } \\
\text { No. }\end{array}$} & $\begin{array}{c}\text { Laser } \\
\text { Power }\end{array}$ & $\begin{array}{c}\text { Hatch } \\
\text { distance }\end{array}$ & $\begin{array}{c}\text { Scan } \\
\text { speed }\end{array}$ & $\begin{array}{c}\text { Layer } \\
\text { thickness }\end{array}$ & $\begin{array}{c}\text { Outline } \\
\text { energy } \\
\text { density }\end{array}$ & $\begin{array}{c}\text { Volume } \\
\text { energy } \\
\text { density }\end{array}$ \\
\cline { 2 - 8 } & $\boldsymbol{W}$ & $\boldsymbol{m m}$ & $\boldsymbol{m m} / \boldsymbol{s}$ & $\boldsymbol{m m}$ & $\boldsymbol{J} / \boldsymbol{m m}$ & $\boldsymbol{J}_{\boldsymbol{m} \boldsymbol{m} \boldsymbol{m}^{3}}$ \\
\hline 1 & 55 & 0.15 & 8000 & 0.08 & 0.0125 & 0.57 \\
\hline 2 & 65 & 0.15 & 8000 & 0.08 & 0.0075 & 0.68 \\
\hline 3 & 55 & 0.25 & 8000 & 0.08 & 0.0075 & 0.34 \\
\hline 4 & 65 & 0.25 & 8000 & 0.08 & 0.0125 & 0.41 \\
\hline 5 & 55 & 0.15 & 12000 & 0.08 & 0.0075 & 0.38 \\
\hline 6 & 65 & 0.15 & 12000 & 0.08 & 0.0125 & 0.45 \\
\hline 7 & 55 & 0.25 & 12000 & 0.08 & 0.0125 & 0.23 \\
\hline 8 & 65 & 0.25 & 12000 & 0.08 & 0.0075 & 0.27 \\
\hline 9 & 55 & 0.15 & 8000 & 0.12 & 0.0075 & 0.38 \\
\hline 10 & 65 & 0.15 & 8000 & 0.12 & 0.0125 & 0.45 \\
\hline 11 & 55 & 0.25 & 8000 & 0.12 & 0.0125 & 0.23 \\
\hline 12 & 65 & 0.25 & 8000 & 0.12 & 0.0075 & 0.27 \\
\hline 13 & 55 & 0.15 & 12000 & 0.12 & 0.0125 & 0.25 \\
\hline 14 & 65 & 0.15 & 12000 & 0.12 & 0.0075 & 0.30 \\
\hline 15 & 55 & 0.25 & 12000 & 0.12 & 0.0075 & 0.15 \\
\hline 16 & 65 & 0.25 & 12000 & 0.12 & 0.0125 & 0.18 \\
\hline 17 & 55 & 0.2 & 10000 & 0.1 & 0.01 & 0.28 \\
\hline 18 & 65 & 0.2 & 10000 & 0.1 & 0.01 & 0.33 \\
\hline 19 & 60 & 0.15 & 10000 & 0.1 & 0.01 & 0.40 \\
\hline 20 & 60 & 0.25 & 10000 & 0.1 & 0.01 & 0.24 \\
\hline 21 & 60 & 0.2 & 8000 & 0.1 & 0.01 & 0.38 \\
\hline 22 & 60 & 0.2 & 12000 & 0.1 & 0.01 & 0.25 \\
\hline 23 & 60 & 0.2 & 10000 & 0.08 & 0.01 & 0.38 \\
\hline 24 & 60 & 0.2 & 10000 & 0.12 & 0.01 & 0.25 \\
\hline 25 & 60 & 0.2 & 10000 & 0.1 & 0.0075 & 0.30 \\
\hline 26 & 60 & 0.2 & 10000 & 0.1 & 0.0125 & 0.30 \\
\hline $27-32$ & 60 & 0.2 & 10000 & 0.1 & 0.01 & 0.30 \\
\hline
\end{tabular}

Design of experiments approach was used to determine the correlations between process parameters, mechanical properties, part density and surface roughness. Due to the complex process correlations in laser sintering, central composite design was utilized in order to include higher order and interaction terms. Laser power, hatch distance, scan speed, layer thickness and outline energy density were selected as influencing factors, resulting in a design of 32 experiments, Table I. The parameter ranges were set by preliminary tests. Reasonably volume energy density range was determined by density measurements. The range was chosen to ensure a drop of density for high energy densities as well as for low energy densities. As a result, values between 0.15 and $0.68 \mathrm{~J} / \mathrm{mm}^{3}$ were used within the experimental design. The ranges of the studied parameters were set appropriate to common values in laser sintering and for the considered High-Speed machine.

Based on the measured data, for all considered properties a second-order response surface model was built up using Design Expert 8 software. The significance of the calculated coefficients was determined using analysis of variance. Based on these results, all non significant coefficients were excluded from the regression equation. Afterwards, the main influencing factors were identified by comparing F-value. Within the paper the only regression models for the part density and the surface roughness are discussed.

\section{RESULTS AND DisCUSSION}

The aim of the study was to establish a correlation between the main influencing factors in regard to mechanical properties, part density and surface roughness. Based 
on the measured values, correlations can be established, describing part properties as a function of volume energy density using polynomials (Fig. 2 to Fig. 7).

\section{A. Part Density and Mechnical Properties}

Fig. 2 shows the results found for the scan vector length dependant part density. In case of small scan vector length (4 to $25 \mathrm{~mm}$ ), density rises for increasing volume energy density and reaches constant level of $1.02 \mathrm{~g} / \mathrm{cm}^{3}$ at 0.30 $\mathrm{J} / \mathrm{mm}^{3}$. For energy input lower than $0.25 \mathrm{~J} / \mathrm{mm}^{3}$ the curves show some differences. The longer the scan vector length the lower is the density. In case of a scan vector length of $150 \mathrm{~mm}$ this effect is most extensive. High densities over $1.01 \mathrm{~g} / \mathrm{cm}^{3}$ are achieved here only for energy densities over $0.40 \mathrm{~J} / \mathrm{mm}^{3}$. However, besides the effect of scan vector length also the change of measuring technique may intensify this effect due to the point that rough and porous surface is included in measuring result in case of $150 \mathrm{~mm}$ density cubes. In contrast to the behavior at low energy densities, all curves show a significant drop of part density over energy input of $0.58 \mathrm{~J} / \mathrm{mm}^{3}$. According to [7], this drop can be correlated to increasing degradation effects. Therefore, dense parts without the occurrence of degradation can be achieved for an energy density range from 0.40 to $0.58 \mathrm{~J} / \mathrm{mm}^{3}$. Compared to the results for Polyamide 12 [24] significant higher energy input is required to reach high densities.

In Fig. 3 the correlation between the young's modulus and the volume energy density is shown. Like for the part density, young's modulus ascends for increasing energy input until a limit of $0.30 \mathrm{~J} / \mathrm{mm}^{3}$. A little drop of the values can be found over an energy density of $0.60 \mathrm{~J} / \mathrm{mm}^{3}$. Within that range nearly constant values of ca. 1600 $\mathrm{N} / \mathrm{mm}^{2}$ (x-direction) and 1500 to $1600 \mathrm{~N} / \mathrm{mm}^{2}$ (zdirection) can be achieved. The results show that in most cases young's modulus in $\mathrm{x}$-direction is a little bit higher than in z-direction. Especially for the x-direction maximum values can be achieved even for lower energy input of $0.25 \mathrm{~J} / \mathrm{mm}^{3}$. However, this value is still significant higher than the value found by Grießbach for Duraform EX. This effect may be caused by differences in the material (in this study EOS PA 1101) or the machine. Within the range from 0.30 to $0.60 \mathrm{~J} / \mathrm{mm}^{3}$ most parameter sets show also little degree of anisotropy with a percentaged deviation of up to $9 \%$.

When considering tensile strength even higher energy input $\left(0.32 \mathrm{~J} / \mathrm{mm}^{3}\right)$ is necessary to reach constant values, Fig. 4. Similar effect was found for PA 12 in [24]. Tensile strength decreases for an energy input of over $0.58 \mathrm{~J} / \mathrm{mm}^{3}$. In contrast to young's modulus the energy processing window becomes smaller. Within the optimal energy density range tensile strength in $\mathrm{x}$-direction reaches values of ca. 48 to $52 \mathrm{~N} / \mathrm{mm}^{2}$ while the values in z-direction vary between 42 and $51 \mathrm{~N} / \mathrm{mm}^{2}$. In most cases tensile strength shows a higher anisotropy with a percentaged deviation of up to $15 \%$ which is very similar to the values found for PA 12 [31].

Fig. 5 shows the correlation between the elongation at break and volume energy density. In case of elongation at break, a minimum energy input of $0.38 \mathrm{~J} / \mathrm{mm}^{3}$ is needed to reach high values for both orientations when also the single experiments are considered. This minimum energy input is the highest for mechanical properties while it is similar to part's density. Like for the tensile strength, energy density should not exceed $0.58 \mathrm{~J} / \mathrm{mm}^{3}$ in order to

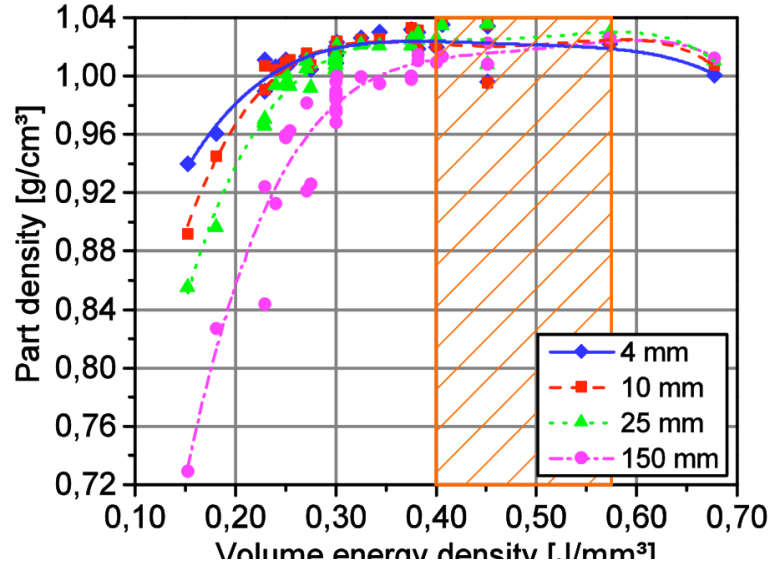

Figure 2. Part density for different scan vector lengths as a fuction of volume energy density

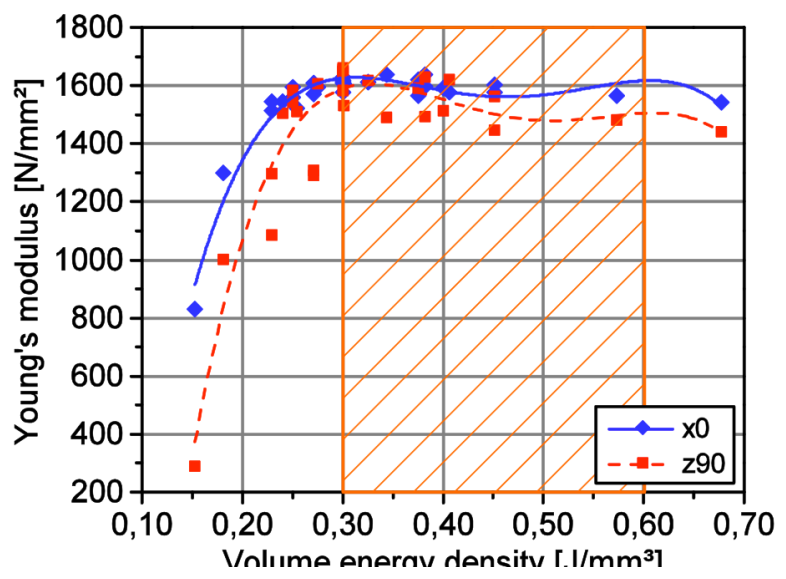

Figure 3. Young's modulus for different specimen orientation as a fuction of volume energy density

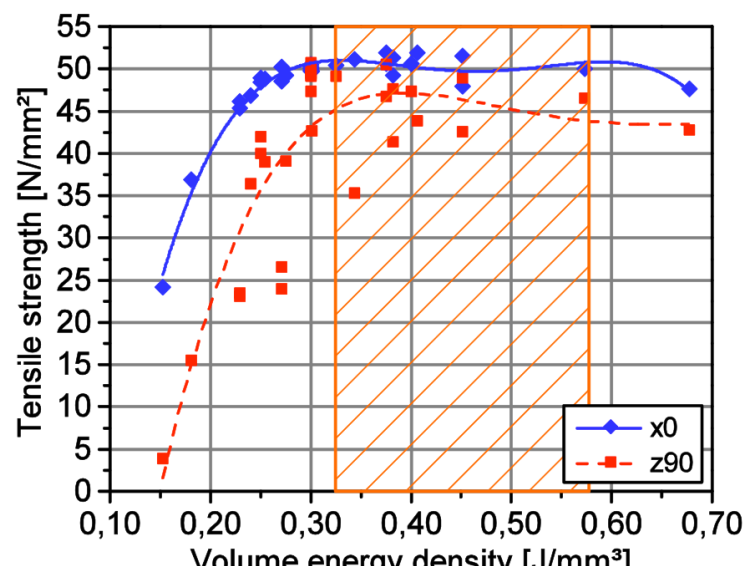

Figure 4. Tensile strength for different specimen orientation as a fuction of volume energy density

avoid a drop of elongation at break caused by degradation. Compared to the other mechanical properties the drop at high energy input is very distinctive with a reduction of over $5 \%$. Within the optimal energy density range, values of 40 to $50 \%$ are reached for the x-direction. Elongation at break in z-direction shows large variance from the fitted trendline with values between 10 and $32 \%$. Like for PA 


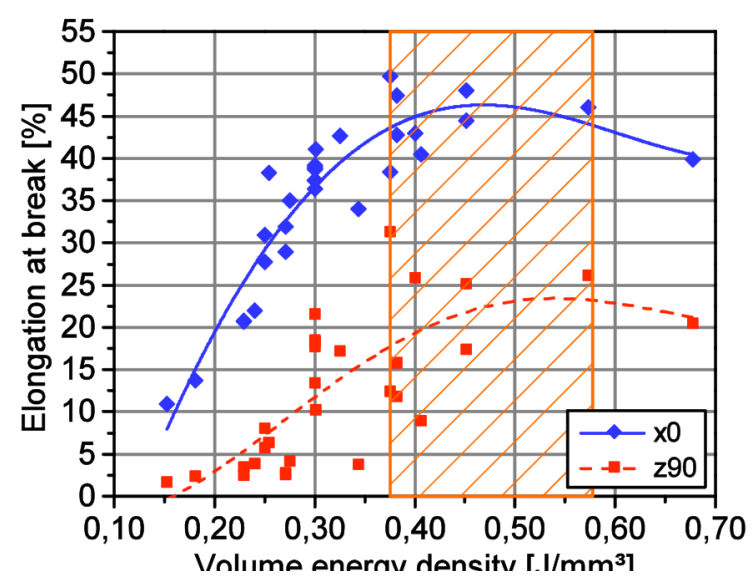

Figure 5. Elongation at break for different specimen orientation as a fuction of volume energy density

12 [24], elongation at break in z-direction shows the highest influence of process parameters. The results for PA 12 indicate that the variance is mainly caused by the different layer thicknesses between 0.080 and $0.12 \mathrm{~mm}$. However, it seems that the effect of layer thickness is even stronger for PA 11 than for PA 12 like the large variance demonstrates. The results in Fig. 4 prove that part orientation has the highest influence on elongation at break, showing significantly lower values for z90. Like for PA 12 [31], elongation of break shows also for PA 11 the highest anisotropy. The percentaged deviation lies within the optimum energy density range at up to $80 \%$. This value is significantly higher than for PA 12 and is mainly caused by the consideration of higher layer thicknesses of 0.12 $\mathrm{mm}$. However, it seems that degree of anisotropy for elongation at break is general higher for PA 11 compared to PA 12.

When all results are summarized, an optimal energy density range can be defined between 0.40 and 0.58 $\mathrm{J} / \mathrm{mm}^{3}$. This range of $0.18 \mathrm{~J} / \mathrm{mm}^{3}$ is much bigger than the optimal range found for PA $12\left(0.05 \mathrm{~J} / \mathrm{mm}^{3}\right)$. Therefore PA 11 has a bigger processing window than PA 12. However a significant higher energy input is necessary to achieve optimal part properties (PA 12: 0.35 to 0.40 $\mathrm{J} / \mathrm{mm}^{3}$ ). When the results for mechanical properties are compared to the data sheet of EOS's PA 1101, a good agreement between the measured values and the data from the sheet can be found. For young's modulus and tensile strength for several parameter sets the data sheet values of $1600 \mathrm{~N} / \mathrm{mm}^{2}$ and $48 \mathrm{~N} / \mathrm{mm}^{2}$ can be reached in x-direction as well as in $\mathrm{z}$-direction. The same result occurs in case of the elongation at break in $\mathrm{x}$-direction. Several points have values above $45 \%$. However, in z-direction only one parameter set (P21) exceeds the data sheet value of $30 \%$.

However, measured values in all diagrams show significant deviations from the fitted trend lines. Models based on energy density are a very simple way to describe correlations in laser sintering, but show only a general interdependency. Detailed information is not given using these correlations. Therefore, second order regression equations should be established in order to describe the correlations in a more detailed way and to predict properties.

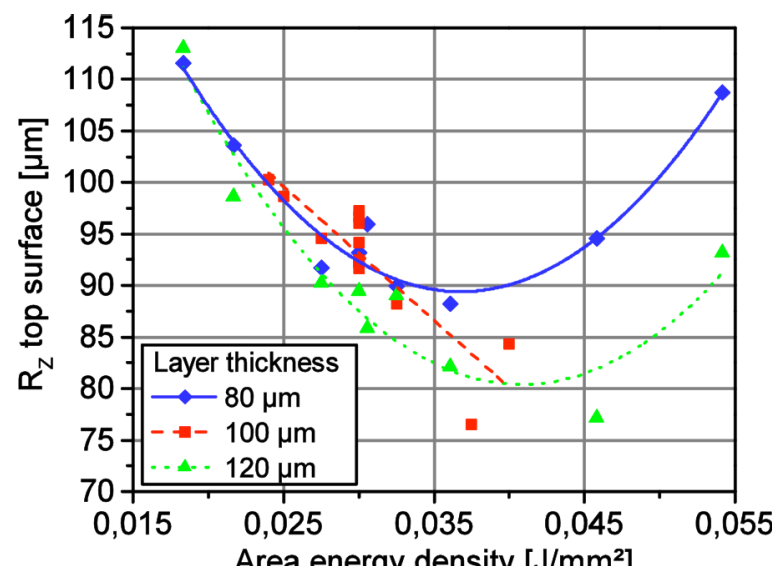

Figure 6. $\mathrm{R}_{\mathrm{Z}}$ of top surface for different layer thicknesses as a fuction of volume energy density

\section{B. Surface Roughness}

Besides mechanical properties and part density, surface roughness was studied. Fig. 6 shows the surface roughness $\mathrm{R}_{\mathrm{Z}}$ of top surfaces as a function of area energy density also distinguishing between the different used layer thicknesses. The results show high roughness values for low as well as for very high energy densities. For a medium energy input a region of low roughness can be found. For a layer thickness of $80 \mu \mathrm{m}$ and $120 \mu \mathrm{m}$ the curves can be described by a second order polynomial while for $100 \mu \mathrm{m}$ a linear trendline fits better due to the lower number of experimental points especially for high energy densities. Within this optimum area $\mathrm{R}_{\mathrm{Z}}$ values in the range between 75 and $90 \mu \mathrm{m}$ can be achieved. Low values can be especially found for area energy densities between 0.03 and $0.05 \mathrm{~J} / \mathrm{mm}^{2}$. Results show that higher layer thickness lead to a lower roughness while at the same time a higher energy input is needed to reach this low values.

In contrast to the top surfaces, for the surface roughness of side surfaces another correlation can be found, Fig. 7. Lowest $R_{Z}$ values of 90 to $100 \mu \mathrm{m}$ are achieved for a layer thickness of $0.1 \mathrm{~mm}$ and an area energy density range from 0.025 to $0.036 \mathrm{~J} / \mathrm{mm}^{2}$. Layer thicknesses of both 120 $\mu \mathrm{m}$ and also $80 \mu \mathrm{m}$ lead to higher roughness. Both curves show a significant increase of $\mathrm{R}_{\mathrm{Z}}$ with rising energy input while the lowest values are found for an area energy density lower than $0.035 \mathrm{~J} / \mathrm{mm}^{2}$. Under this limit, $\mathrm{R}_{\mathrm{Z}}$ values lie for a layer thickness of $120 \mu \mathrm{m}$ between 110 and 130 $\mu \mathrm{m}$. For $80 \mu \mathrm{m}$, surface roughness lies between 100 and $110 \mu \mathrm{m}$. However, it is surprising that the lowest roughness values result not from the lowest layer thickness like the results in [27] indicate for PA 12. One possible reason for that behavior might be that the powder contains several particles larger than the particle size which makes it more difficult to form a flat layer with clearly defined edges.

When the results for both surfaces are compared, an optimal energy density range can be defined to achieve low surface roughness. Area energy input should lie between 0.03 and $0.04 \mathrm{~J} / \mathrm{mm}^{2}$ while the layer thickness is set to 0.1 $\mathrm{mm}$. 


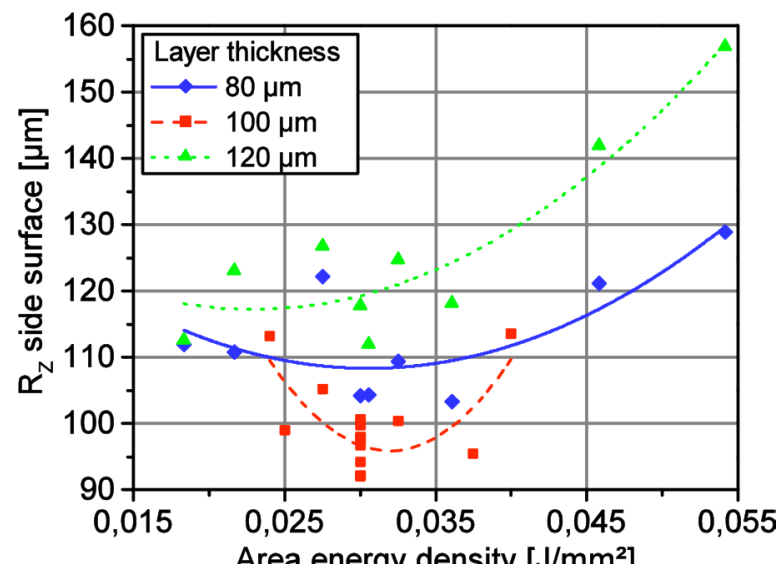

Figure 7. $\mathrm{R}_{\mathrm{Z}}$ of side surface for different layer thicknesses as a fuction of volume energy density

\section{REGRESSION MODELS}

Based on the measured data for part density and surface roughness, regression equations were established using Design Expert. The significance of terms in each equation, as well as the significance of the model and of the lack of fit, was evaluated using analysis of variance. Significance level is achieved for $\mathrm{p}$-values below 0.05. Coefficients failing the significance were excluded from the equations. However, in some models non significant terms were not excluded for hierarchic reasons. All established models show a non significant lack of fit, resulting in adequate models, also having high R-Squared values of over 0.95 , Table II. Additionally, all models show high values over 0.85 for the adjusted and the predicted R-Squared with a reasonable agreement of both values, Table II. Therefore, all models are adequate to make predictions within the design space. However, in all models some data test points had to be excluded as outliers in order to achieve a fitting model.

The model equations show significant differences regarding the included terms as well as their numbers. Most of them contain, aside from linear terms, higher order, as well as multiple interaction terms, demonstrating a complex corre-lation between process parameters and part properties. This emphasizes the intricate interaction of process parameters in laser sintering. Lowest influence is given by the higher order term of the outline energy density $\mathrm{E}^{2}$, which is included in none model. Additionally, based on the F-values of ANOVA the four main influences were identified in all models. These are marked by different colors (red to green) basing on their influence rank. Red marks the highest influence.

When comparing all four models for the part density, this is mainly influenced by linear effect of the laser power A as well as by the interaction of hatch distance and scan speed BC. Additionally, for longer cubes (25 $\mathrm{mm}$ and $150 \mathrm{~mm}$ ) scan speed $\mathrm{C}$ has a high influence while for small cubes ( $4 \mathrm{~mm}$ and $10 \mathrm{~mm}$ ) the layer thickness $\mathrm{D}$ has a higher influence. For the smallest cube also the interaction of the outline energy density and the hatch distance BE respectively scan speed CE show a high influence. This might be caused by the higher surface volume compared to the small fill volume for this cube size. Therefore, the outline has a bigger influence on density. For $10 \mathrm{~mm}$ and $25 \mathrm{~mm}$ cubes, the interaction of
TABLE II.

ESTABLISHED REGRESSION MODELS BASED ON THE COEFFIENTS OF THE REGRESSION POLYNOM

\begin{tabular}{|c|c|c|c|c|c|c|}
\hline & $\begin{array}{c}\text { Part } \\
\text { density }\end{array}$ & $\begin{array}{c}\text { Part } \\
\text { density }\end{array}$ & $\begin{array}{c}\text { Part } \\
\text { density }\end{array}$ & $\begin{array}{c}\text { Part } \\
\text { density }\end{array}$ & $\begin{array}{c}\text { Surface } \\
\text { Roughness } \\
\boldsymbol{R}_{\boldsymbol{Z}}\end{array}$ & $\begin{array}{c}\text { Surface } \\
\text { Roughness } \\
\boldsymbol{R}_{\boldsymbol{Z}}\end{array}$ \\
\cline { 2 - 7 } & $\mathbf{4} \mathbf{m m}$ & $\mathbf{1 0} \mathbf{m m}$ & $\mathbf{2 5} \mathbf{m m}$ & $\mathbf{1 5 0} \mathbf{m m}$ & $\boldsymbol{t o p}$ & side \\
\hline & 1.017 & 1.016 & 1.010 & 0.981 & 93.2 & 96.8 \\
\hline $\mathrm{A}$ & 0.011 & 0.010 & 0.017 & 0.030 & -1.9 & 1.0 \\
\hline $\mathrm{B}$ & -0.007 & -0.008 & -0.015 & -0.040 & 5.5 & -2.5 \\
\hline $\mathrm{C}$ & -0.003 & -0.008 & -0.013 & -0.027 & 4.2 & -8.6 \\
\hline $\mathrm{D}$ & -0.012 & -0.012 & -0.012 & -0.024 & -2.1 & 6.5 \\
\hline $\mathrm{E}$ & 0.001 & 0.003 & 0.003 & 0.010 & 0.7 & -0.1 \\
\hline $\mathrm{AB}$ & 0.007 & 0.013 & 0.018 & 0.014 & -1.4 & -2.1 \\
\hline $\mathrm{AC}$ & 0.006 & 0.007 & 0.012 & 0.011 & -2.5 & -- \\
\hline $\mathrm{AD}$ & 0.005 & 0.010 & 0.012 & 0.018 & 1.3 & 2.3 \\
\hline $\mathrm{AE}$ & -- & -0.006 & -- & -- & -- & -- \\
\hline $\mathrm{BC}$ & -0.003 & -0.015 & -0.014 & -0.033 & 4.1 & 5.4 \\
\hline $\mathrm{BD}$ & -- & -0.006 & -0.005 & -- & 1.4 & -2.4 \\
\hline $\mathrm{BE}$ & 0.010 & 0.004 & 0.006 & -- & -1.6 & -- \\
\hline $\mathrm{CD}$ & 0.004 & -0.007 & -0.006 & -- & -- & -2.1 \\
\hline $\mathrm{CE}$ & 0.011 & 0.009 & 0.010 & -- & -2.1 & -- \\
\hline $\mathrm{DE}$ & 0.005 & -- & 0.003 & 0.015 & -- & 2.6 \\
\hline $\mathrm{A}^{2}$ & -- & -- & -0.006 & -0.012 & -- & 5.4 \\
\hline $\mathrm{B}^{2}$ & -0.004 & -0.006 & -- & -0.013 & -- & 15.9 \\
\hline $\mathrm{C}^{2}$ & -- & -- & -- & -- & -- & -11.1 \\
\hline $\mathrm{D}^{2}$ & 0.004 & -- & -- & -- & -- & 13.5 \\
\hline $\mathrm{E}^{2}$ & -- & -- & -- & -- & -- & -- \\
\hline $\mathrm{R}^{2}$ & 0.994 & 0.994 & 0.994 & 0.987 & 0.950 & 0.978 \\
\hline $\mathrm{R}^{2}{ }_{\text {adj }}$ & 0.988 & 0.987 & 0.989 & 0.979 & 0.915 & 0.955 \\
\hline $\mathrm{R}^{2}$ pred & 0.945 & 0.919 & 0.936 & 0.936 & 0.856 & 0.895 \\
\hline & & & & & & \\
\hline
\end{tabular}

laser power and hatch distance $\mathrm{AB}$ is a main influence while for $150 \mathrm{~mm}$ linear effect of hatch distance B shows the highest influence in the model. When these main influences on part density of PA 11 are compared to PA 12 $[7,24]$ some similarities as well as some significant differences can be found. The linear influences of laser power, scan speed and layer thickness show main influences for both materials. In contrast to PA 12, for PA 11 linear effect of hatch distance has a smaller influence on density being main influence only in one model instead of all models. Additionally, almost all influencing factors show the same effect direction in all four models. Therefore, an optimization of the parameters has always same effect independent from the scan vector length. However, the effect size is different.

Additionally, the influences on surface roughness were studied, Table II. The established models show significant differences between the considered surfaces. Main influences for the top surface are the linear effect of hatch distance $\mathrm{B}$ and the scan speed $\mathrm{C}$ as well as the interaction of laser power and scan speed AC and the interaction of hatch distance and scan speed BC. Therefore, as expected outline parameters and layer thickness show only little influence on the surface roughness of top surfaces. The roughness of the side surfaces shows some other influences. Main influences are the linear effect of the scan speed $\mathrm{C}$ and the layer thickness $\mathrm{D}$, the interaction of hatch distance and scan speed $\mathrm{BC}$ as well as the higher order term of the hatch distance $\mathrm{B}^{2}$. Compared to the top surface, layer thickness has for the side surface a much bigger influence as found in [27] also for PA 12. However in contrast to PA 12, the roughness is hardly influenced by the outline parameters but mainly by the fill parameters.

Basing on the established regression models, an improved parameter set can be calculated using numerical 
optimization. This lead to high densities of $1.032 \pm 0.004$ $\mathrm{g} / \mathrm{cm}^{3}$ independent from the scan vector length as well as to low surface roughness of $88 \mu \mathrm{m}$ independent from the surface orientation. To achieve these values laser power should be $63 \mathrm{~W}$, hatch distance $0.16 \mathrm{~mm}$, scan speed $12000 \mathrm{~mm} / \mathrm{s}$, layer thickness $0.1 \mathrm{~mm}$ and outline energy density $0.01 \mathrm{~J} / \mathrm{mm}$. After establishing the regression models for the mechanical properties, these should be added to the numerical optimization in order to achieve optimal process parameters considering mechanical properties, part density and surface roughness.

\section{CONCLUSIONS}

Within the results presented, design of experiments was used to establish correlations between process parameters and different part properties. In a first step, the correlation between part properties and energy density was studied. Based on these results, optimal ranges for the energy input can be defined. For the considered EOS PA 1101 a range of 0.4 to $0.58 \mathrm{~J} / \mathrm{mm}^{3}$ leads to optimal part properties. It was found that the processing of PA 11 using the DTM Sinterstation 2500 HS requires significant higher energy input. However, compared to PA 12 the processing window is circa 1.5 to 2 times larger. In a second step, response surface models was established in order to correlate five influencing factors with the part density and the surface roughness also considering different part length and part orientation. These correlation models demonstrate the complex correlations of process parameters in laser sintering, in most cases showing a non-linear nature with multiple parameter interactions. Additionally, the four main influences on part density and surface roughness of polyamide 11 parts were identified being laser power, hatch distance, scan speed, layer thickness and interaction of hatch distance and layer thickness. Similar influences were found for Polyamide 12. The results presented here provide, for the first time, detailed information on the correlation between process parameters and part properties when processing polyamide 11 in laser sintering resulting in an enhanced understanding of the laser sintering process and also allowing for the prediction and optimization of part properties.

Future work should validate the investigated correlations. Additionally, second order response surface models should be established also for the mechanical properties in order to optimize process parameter considering multiple part properties. Further, results should be compared with the processing of PA 1101 on an EOS Formiga P100 using similar parameter ranges but a 2.7-times lower scan speed and higher laser power. Some first results are presented in Fig. 8. Optimal densities are achieved in this case for energy densities between 0.25 and $0.45 \mathrm{~J} / \mathrm{mm}^{2}$. Therefore a significant lower energy input is required to reach a high density. Additionally, for the Formiga significant stronger degradation effects are found especially for energy densities over $0.58 \mathrm{~J} / \mathrm{mm}^{3}$.

Additional research should compare the results for the uncolored PA 1101 from EOS with the processing of Arkema's Rilsan Invent black. Furthermore, the melt temperatures during processing should be analyzed using High-Speed-thermal imaging. Afterwards, the long-term properties of laser sintered PA 11 parts should be studied by comparing optimized parameter sets with material and machine manufacturer's default parameter set.

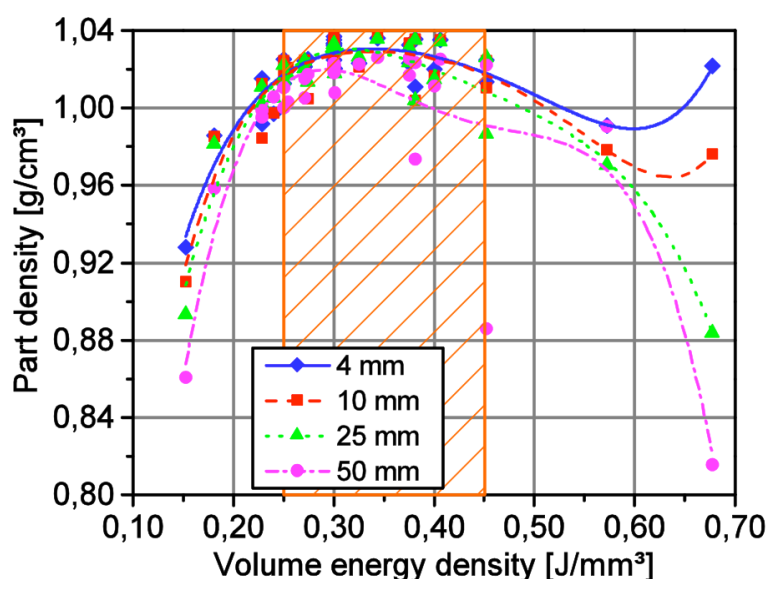

Figure 8. Part density for different scan vector lengths as a fuction of volume energy density (EOS Formiga P100)

\section{ACKNOWLEDGMENT}

The IGF project (17945N) with the title "Resource Saving Small Series Production by Polymer Laser Sintering Stabilization of the Long-Term Properties of Laser Sintered Parts (LZE-LS)" of the research association Institute of Energy and Environmental Technology e.V. (IUTA) was founded by the Federal Ministry of Economics and Energy via the AiF within the programm for funding industrial joint research based on a decission of the German Bundestag.

The study is performed within a cooperation project between the Chair of Manufacturing Technology (University of Duisburg-Essen) and the Institute of Polymer Technology (University of Erlangen-Nuremberg).

\section{REFERENCES}

[1] E. Abele, "Herausforderungen für die Produktion(sforschung) 2020," Presentation on the 10th Karlsruher Arbeitsgespräche Produktions-forschung 2010. Karlsruhe, BMBF, 2010.

[2] R. Hague, I. Campell and P. Dickens, "Implications on design of rapid manufacturing," Proc. of the Inst. of Mech. Eng., Part C: J. of Mech. Eng. Sci., vol. 217 no. 1, pp. 25-30, 2003. http://dx.doi.org/10.1243/095440603762554587

[3] N. N., VDI-Guideline 3404 - Additive fabrication - Rapid technologies - Fundamentals, terms and definitions, quality parameters, supply agreements. Association of German Engineers, 2009.

[4] A. Gebhardt, Generative Fertigungsverfahren - Rapid Prototyping - Rapid Tooling - Rapid Manufacturing. $3^{\text {rd }}$ ed., Munich: Carl Hanser Publishing, 2007.

[5] Schmachtenberg and T. Seul, "Model of isothermic lasersintering," Proc. of the Antec Conf. 2002, Society of Plastics Engineers, San Francisco, California, 2002.

[6] D. Rietzel, Werkstoffverhalten und Prozessanalyse beim LaserSintern von Thermoplasten, Ph.D. Thesis, Friedrich-Alexander Universität Erlangen-Nürnberg, 2011.

[7] A. Wegner and G. Witt, "Understanding the decisive thermal processes in laser sintering of polyamide 12," Proc. of the Poly. Proc. Soc. 30th Annual Meeting PPS-30, Cleveland, Ohio (USA), Poly. Proc. Soc., pp. S15-228, 2014.

[8] J. C. Nelson, Selective Laser Sintering: A Definition of the Process and an Empirical Sintering Model, PhD-Thesis, University of Texas at Austin, 1993.

[9] T. L. Starr, Gornet, and J. S. Usher, "The Effect of Process Conditions on Mechanical Properties of Laser-Sintered Nylon," Rapid Prototyping J., vol. 17 no. 6, pp. 418-423, 2011. http://dx.doi.org/10.1108/13552541111184143

[10] W. Kaddar, Die generative Fertigung mittels Laser-Sintern: Scanstrategien, Einflüsse verschiedener Prozessparameter auf die 
PAPER

Determination of Optimal Processing Conditions for the Production of Polyamide 11 Parts using the...

mechanischen und optischen Eigenschaften beim LS von Thermoplasten und deren Nachbearbeitungsmöglichkeiten. $\mathrm{PhD}$ thesis, University of Duisburg-Essen, 2010.

[11] I. Gibson and D. Shi, "Material properties and fabrication parameters in selective laser sintering process," Rapid Prototyping J., vol. 3 no. 4, pp. 129-136, 1997. http://dx.doi.org/10.1108/1355254 9710191836

[12] H. C. H. Ho, I. Gibson and W. L. Cheung, "Effect of energy density on morphology and properties of selective laser sintered polycarbonate," J. of Mat. Proc. Tech., vol. 89-90, pp. 204-210, 1999. http://dx.doi.org/10.1016/S0924-0136(99)00007-2

[13] B. Caulfield, P. E. McHugh and S. Lohfeld, "Dependence of mechanical properties of polyamide components on build parameters in the SLS process," J. of Mat. Proc. Tech., vol. 182, pp. 477488, 2007. http://dx.doi.org/10.1016/j.jmatprotec.2006.09.007

[14] A. E. Tontowi, Selective Laser Sintering of Crystalline Polymers: $\mathrm{PhD}$ thesis, University of Leeds, 2000.

[15] A. Sauer, Optimierung der Bauteileigenschaften beim Selektiven Lasersintern von Thermoplasten: PhD thesis, University of Duisburg-Essen, 2005.

[16] P. K. Jain, P. M. Pandey and P. V. M. Rao, "Effect of delay time on part strength in selective laser sintering," Int. J. of Adv. Man. Tech., vol. 43 no. 1-2, pp. 117-126, 2009. http://dx.doi.org/10.1007/s00170-008-1682-3

[17] S. Rüsenberg, L. Schmidt and H.-J. Schmid, "Mechanical and physical properties - a way to assess quality of laser sintered parts," Proc. of the $22^{\text {nd }}$ Int. Solid Freeform Fabrication Symp. 2011, Austin, Texas, pp. 239-251, 2011

[18] A. Pilipovic, B. Valentin, T. Brajlih, et al., "Influence of laser sintering parameters on mechanical properties of polymer products," Annals of DAAAM for 2010 \& Proc. of $3^{\text {rd }}$ Int. Conf. on Additive Tech. (ICAT 2010), DAAAM International Organisation, pp. 285-286, 2010.

[19] A. Ghanekar, R. Crawford and D. Watson, "Optimization of SLS process parameters using d-optimality," Proc. of the $14^{\text {th }}$ Int. Solid Freeform Fabrication Symp. 2003, Austin Texas, pp. 348-362, 2003.

[20] P. K: Jain, M. Pulak, P. V. Pandey and M. Rao, "Experimental investigations for improving part strength in selective laser sintering," Virtual and Physical Prototyping, vol. 3 no. 3, pp. 177-188, 2008. http://dx.doi.org/10.1080/17452750802065893

[21] V. E. Beal, R. A. Paggi, G. V. Salmoria and A. Lago, "Statistical evaluation of laser energy density effect on mechanical properties of polyamide parts manufactured by selective laser sintering," $J$. of Applied Poly. Sci., vol. 113, pp. 2910-2919, 2009. http://dx.doi.org/10.1002/app.30329

[22] M. Monzón, P. M. Hernández, A. N. Benítez, M. D. Marrero and A. Fernández, "Predictability of plastic parts behaviour made from rapid manufacturing," Tsinghua Sci. and Tech., vol. 14 no. 1, pp. 100-107, 2009. http://dx.doi.org/10.1016/S1007-0214(09)70075-6

[23] A. K. Singh and R. S. Prakash, "Response surface-based simulation modeling for selective laser sintering process," Rapid Prototyping J., vol. 16 no. 6, pp. 441-449, 2010. http://dx.doi.org/10.1108/13552541011083362
[24] A. Wegner and G. Witt, "Correlation of process parameters and part properties in laser sintering using response surface modeling," Phys. Proc., vol. 39, pp. 480-490, 2012http://dx.doi.org/10.1016/ j.phpro.2012.10.064

[25] A. Wegner and G. Witt, "Correlation between melt's temperature during laser exposure and part properties in laser sintering," Proc. of the 4th Int. Conf. on Additive Technologies (ICAT 2012), DAAAM Int. Organisation, 2012.

[26] A. Wegner, T. Grimm and G. Witt, "Improvement of the reproducibility of laser sintered polyamide 12 parts by establishment of robust processing conditions using propagation of error method," Proc. of the Fraunhofer Direct Digital Man. Conf. 2014, Berlin, 2014.

[27] A. Wegner and G. Witt, "Influencing factors on surface roughness in laser sintering and their effect on process speed," Proc. of the Fraunhofer Direct Digital Man. Conf. 2012, Berlin, 2012.

[28] B. Keller, Rapid Prototyping: Grundlagen zum selektiven Lasersintern von Polymerpulver, PhD-Thesis, University of Stuttgart, 1998.

[29] R. D. Goodridge, R. J. M. Hague and C. J. Tuck, “An empirical study into laser sintering of ultra-high molecular weight polyethylene (UHMWPE)," J. of Mat. Proc. Tech., vol. 210, pp. 72-80, 2010. http://dx.doi.org/10.1016/j.jmatprotec.2009.08.016

[30] S. Grießbach, Korrelation zwischen Materialzusammensetzung, Herstellungsbedingungen und Eigenschaftsprofil von lasergesinterten Polyamid-Werkstoffen, PhD-Thesis, Martin-LutherUniversity Halle-Wittenberg, 2012.

[31] A. Wegner and G. Witt, "Laser sintered parts with isotropic mechanical properties," Tech. Paper - Soc. of Man. Eng., TP12PUB43, pp. 1-16, 2012.

\section{AUTHORS}

A. Wegner is Scientific Assistant on the chair of Manufacturing Technology at the University of Duisburg-Essen, 47057 Duisburg, Germany (e-mail: andreas.wegner@unidue.de).

R. Harder, is Scientific Assistant on the Institute of Polymer Technology at the University of ErlangenNuremberg, 91058 Erlangen, Germany (e-mail: harder@lkt.uni-erlangen.de).

Prof. G. Witt is chairholder the chair of Manufacturing Technology at the University of Duisburg-Essen, 47057 Duisburg, Germany (e-mail: gerd.witt@uni-due.de).

Prof. D. Drummer is chairholder of the Institute of Polymer Technology at the University of ErlangenNuremberg, 91058 Erlangen, Germany (e-mail: drummer@lkt.uni-erlangen.de).

This article is an extended and modified version of a paper presented at the International Conference on Additive Technologies (ICAT2014), held from 15-17 October 2014 in Vienna, Austria. Submitted, 20 November 2014. Published as resubmitted by the authors on 10 March 2015. 